\title{
ANALISIS OPERASIONAL WADUK PANGSAR SOEDIRMAN UNTUK REDUKSI PENINGKATAN SEDIMEN MASUK
}

\section{PANGSAR SOEDIRMAN RESERVOIR OPERATIONAL ANALYSIS FOR REDUCTION OF INCREASED SEDIMENT}

\author{
Teguh Marhendi \\ Program Studi S1 Teknik Sipil, Fakultas Teknik dan Sains \\ Universitas Muhammadiyah Purwokerto
}

\section{Informasi Artikel}

Dikirim, 7 Oktober 2021

Direvisi, 4 November 2021

Diterima, 15 Desember 2021

\section{Korespondensi Penulis:}

Teguh Marhendi

Program Studi Teknik Sipil

Universitas Muhammadiyah

Purwokerto

JL. K.H. Ahmad Dahlan

Purwokerto, 53182

Email:

tmarhendi@gmail.com

\begin{abstract}
ABSTRAK
Perkembangan peningkatan sedimentasi yang masuk Waduk Pangsar Soedirman sejak tahun 1989 hingga tahun 2018 sudah mencapai 77\% atau sekitar 114 juta $\mathrm{m}^{3}$. Beberapa pemicu peningkatan sedimentasi di Waduk Pangsar Soedirman antara lain perubahan penggunaan lahan di Daerah Aliran Sungai bagian hulu dan faktor kelerengan lahan. Peningkatan sedimentasi ini mendorong pihak pengelola Waduk Pangsar Soedirman untuk melakukan upaya mengurangi peningkatan sedimentasi yang masuk ke waduk. Kegiatan Flushing menjadi salah satu upaya yang rutin dilakukan sepanjang tahun dengan jumlah yang bervariasi antara 2 hingga 30 kali dalam setahun. Penelitian ini bertujuan untuk menganalisis efektivitas flushing dalam upaya reduksi sedimentasi terhadap valume air waduk yang terbuang saat pelaksanaan. Data penelitian berupa data Sedimen dan data Flushing Waduk Mrica periode tahun 1992-2018. Hasil analisis menunjukkan bahwa jumlah total sedimentasi yang terbuang selama ini dari tahun 1992 2018 sebesar $13.058 .611,99 \mathrm{~m}^{3}$ atau 3,327 \% dari total air dan sedimen yang terbuang saat flushing. Sedangkan volume air yang terbuang sebesar $379.389 .296,00 \mathrm{~m}^{3}$ atau $96,673 \%$ atau efektivitas penggunaan model flushing terhadap reduksi peningkatan sedimen sebesar $3,44 \%$.
\end{abstract}

Kata Kunci : Penataan Hulu, Reduksi Peningkatan Sedimentasi, Waduk Pangsar Soedirman

The development of increased sedimentation entering the Pangsar Sudirman Reservoir from 1989 to 2018 has reached $77 \%$ or around 114 million $\mathrm{m}^{3}$. Several triggers for increased sedimentation in the Pangsar Sudirman Reservoir include changes in land use in the upstream watershed and land slope factors. This increase in sedimentation encourages the manager of the Pangsar Sudirman Reservoir to make efforts to reduce the increase in sedimentation that enters the reservoir. Flushing activities are one of the efforts that are routinely carried out throughout the year with the amount varying from 2 to 30 times a year. This study aims to analyze the effectiveness of flushing in an effort to reduce sedimentation on the volume of wasted reservoir water during implementation. The research data are in the form of sediment data and Mrica Reservoir Flushing data for the period 1992-2018. The results of the analysis show that the total amount of sediment that was wasted so far from 1992-2018 was 13,058,611.99 $\mathrm{m} 3$ or $3.327 \%$ of the total water and sediment that was wasted during flushing. While the volume of wasted water is $379,389,296.00 \mathrm{~m} 3$ or 96,673\% or the effectiveness of using the flushing model to reduce sediment increase is $3,44 \%$.

Keyword : Upstream Arrangement, Reduction of Sedimentation Improvement, Pangsar Sudirman 


\section{PENDAHUluaN}

Peningkatan laju erosi dan sedimentasi daerah tangkapan air waduk masih menjadi permasalahan utama dalam pengelolaan waduk di Indonesia. Waduk-waduk besar di Indonesia hampir mengalami permasalahan tersebut, termasuk Waduk Pangsar Soedirman. Sedimen yang mengendap di atas tampungan mati akan mengurangi volume efektif waduk. Beberapa permasalahan lain yang timbul akibat sedimentasi ini adalah berkurangnya kapasitas tampungan waduk yang mengakibatkan berkurangnya kapasitas pengendalian banjir, produksi listrik dan pangan [1] [2] [3].

Waduk Panglima Soedirman atau juga dikenal dengan nama Waduk Mrica, mengalami peningkatan sedimentasi yang cukup tinggi. Sampai dengan tahun 2017 perkembangan kumulatif sedimen di Waduk Pangsar Soedirman mencapai 114 juta $\mathrm{m}^{3}$ sebagaimana dapat dilihat pada Gambar 1 [2] [3]. Dengan perkembangan sedimentasi yang terus meningkat, maka dapat diperkirakan, kondisi saat ini kapasitas wadu $k$ terus mengalami pengurangan.

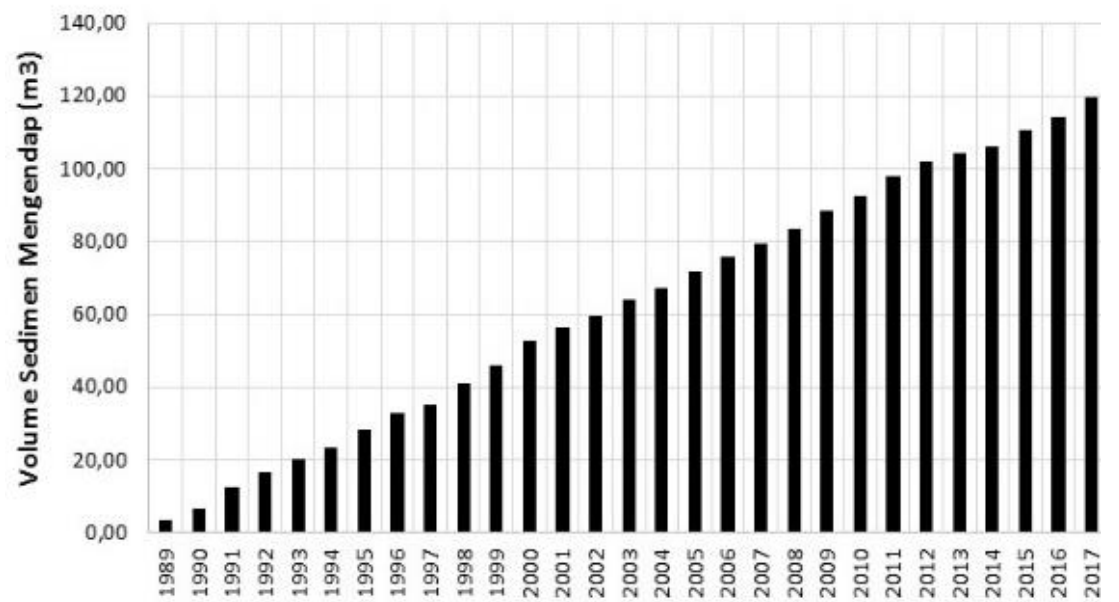

Gambar 1. Perkembangan Kumulatif Sedimen di Waduk Pangsar Soedirman 1989-2017 [3]

Evaluasi perkembangan sedimen di Waduk Pangsar Soedirman, terus dilakukan oleh pihak PT. Uni Indonesia Power UBP Waduk Pangsar Soedirman. Salah satu bentuk evaluasi adalah dilakukan secara rutin pengukuran kedalaman waduk dengan metode Echosounding. Gambar 4 di atas, menunjukkan sebagian hasil evaluasi melalui Echosounding. Beberapa evaluasi lain juga pernah dilakukan oleh pihak ketiga, misalnya penelitian dari SMEC laju erosi di DTA tahun 1975-1978 rata-rata adalah 3,6 mm/tahun, WIDHA tahun 1988 mengadakan penelitian dan hasilnya menunjukkan bahwa laju erosi rata-rata 2,46 mm/tahun [2] [3] [4]. Berdasarkan penelitian dari Pusat Penyelidikan Masalah Kelistrikan PT. PLN dengan Universitas Gajah Mada tahun 1995 dengan menggunakan formula USLE didapat laju erosi pada DAS Merawu 4,7 mm/tahun, pada DAS Serayu 3,1 mm/tahun, dan di luar DAS Merawu dan Serayu 2,7 mm/tahun [5] [6] [1] [7] [8].

Evaluasi peningkatan tidak hanya dilakukan melalui pengukuran kedalaman dasar waduk tetapi juga dilakukan upaya teknis pengurangan sedimen melalui kegiatan flushing. Flushing dilakukan dengan membuka pintu drawdown culvert pada waduk untuk membuang sedimen. PT. Uni Indonesia Power UBP Waduk Pangsar Soedirman sepanjang tahun 1996-2018 rutin melakukan kegiatan flusing. Rata-rata dalam satu tahun dilakukan sebanyak 2-30 kali tiap periode pelaksanaan. Upaya yang dilakukan tersebut, belum menjadikan pengurangan sedimen yang masuk waduk berkurang secara signifikan.

\section{METODE PENELITIAN}

Metode penelitian menguraikan cara yang digunakan untuk menyelesaikan masalah, meliputi alat, bahan dan metode yang digunakan dalam pemecahan masalah.

\subsection{Gambaran Lokasi Penelitian}

Lokasi penelitian berada pada Waduk Pangsar Soedirman, Bawang, Banjarnegara pada koordinat $109^{\circ} 06^{\prime} 00^{\prime \prime}-110^{\circ} 07^{\prime} 49^{\prime \prime}$ BT dan 7¹7'04” - 747’07’ LS. 


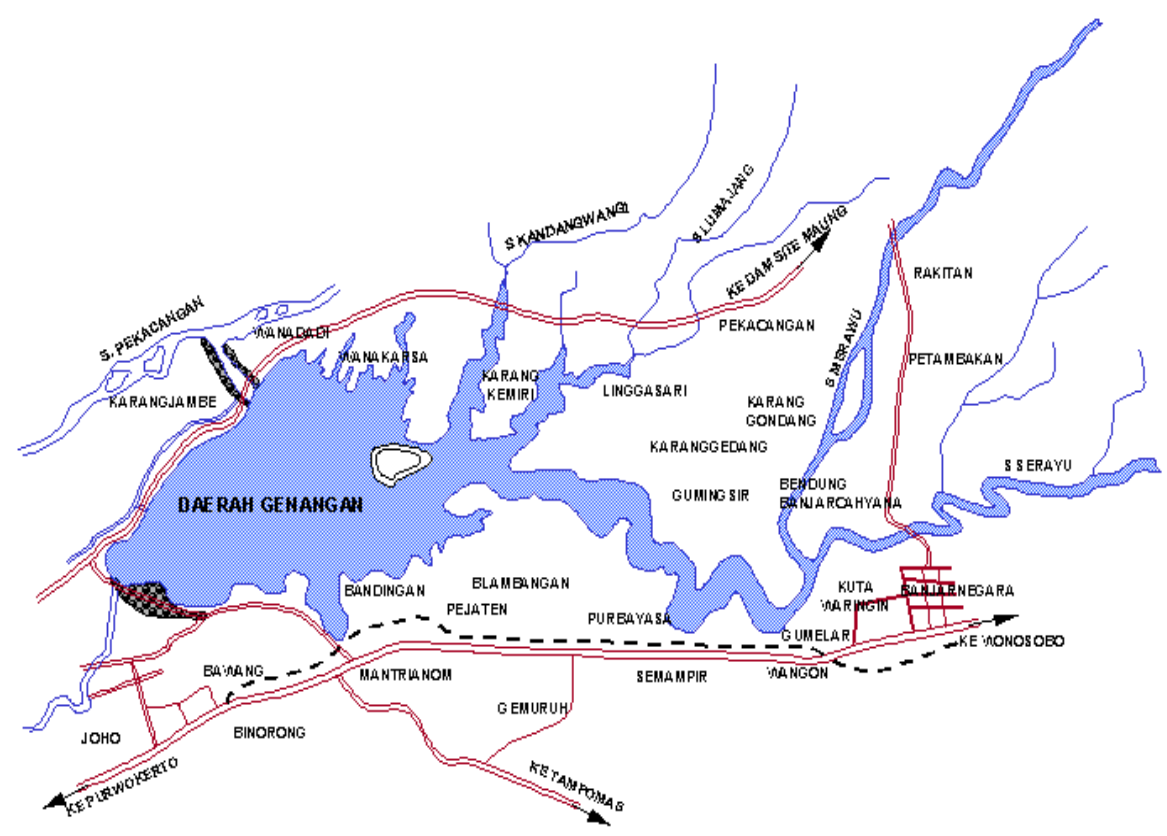

Gambar 2. Lokasi Penelitian [6]

\subsection{Pengumpulan Data}

Data dalam penelitian ini meliputi:

1). Data pengukuran/pencatatan sedimentasi di Waduk Pangsar Soedirman 1992-2018

2). Data pengukuran/ pencatatan debit air dan Sedimen melalui flushing 1992-2018

3). Peta Daerah Tangkapan Air Waduk Pangsar Soedirman

Data-data tersebut berasal dari dinas/ instansi terkait pengelolaan Waduk Pangsar Soedirman dalam hal ini dari PT. Uni Indonesia Power UBP Waduk Pangsar Soedirman.

\subsection{Langkah-Langkah Penelitian}

\subsubsection{Analisis Kumulatif Volume Sedimen}

Analisis kumulatif volume sedimen dilakukan untuk memperoleh gambaran inflow sedimen dan kumulatif sedimen mengendap di waduk. Dari analisis ini akan diperoleh gambaran peningkatan/perubahan volume kumulatif sedimen inflow dan yang mengendap di waduk pertahun sehingga dapat diketahui perubahan perkembangan inflow sedimen yang masuk ke waduk. Kumulatif volume sedimen dianalisis dalam bentuk grafik perkembangan sedimen waduk.

\subsubsection{Analisis Pengurangan Sedimen Menggunakan Model Flushing}

Salah satu bentuk upaya pengurangan sedimen yang dilakukan di Waduk Pangsar Soedirman adalah menggunakan model flushing. Flushing dilakukan dengan cara membuang air beserta sedimen yang mengendap di waduk melalui pintu drawdown culvert. Analisis dilakukan dengan menentukan besaran debit air yang terbuang dan debit sedimen yang dapat dikeluarkan selama proses flushing dilakukan sepanjang tahun 2002-2018. 


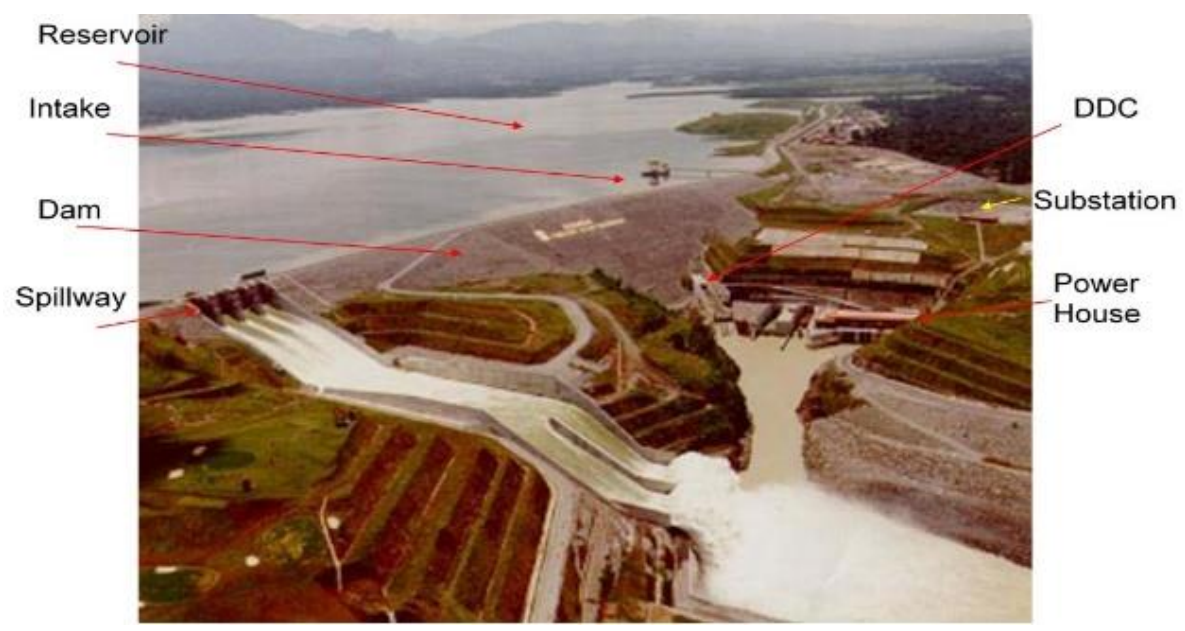

Gambar 3. Posisi Drawdown Culvert pada Proses Flushing [3]

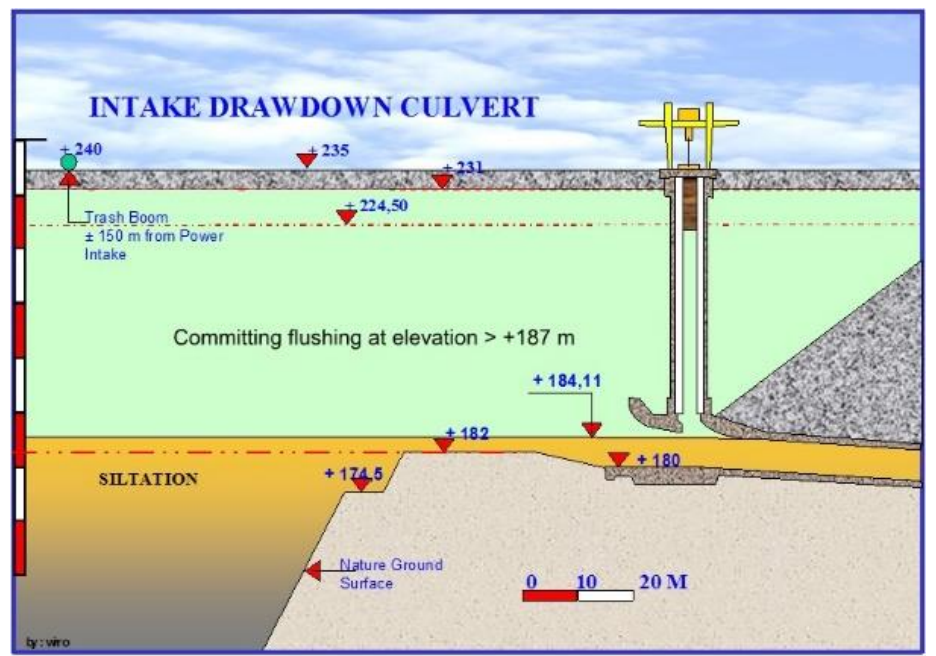

Gambar 4. Pintu Intake pada sistem drawdown Culvert untuk Flushing [3]

\subsubsection{Analisis Efektivitas Flushing terhadap reduksi sedimen}

Analisis efektivitas flushing dimaksudkan untuk menentukan besaran prosentase debit sedimen dan debit air yang harus dibuang selama proses berlangsung, sehingga dapat diketahui apakah model flushing ini dapat dikembangkan untuk mereduksi peningkatan sedimen selama umur waduk berlangsung menggunaklan model statistika.

\section{HASIL DAN PEMBAHASAN}

\subsection{Analisis Reduksi volume Sedimentasi melalui Aktivitas Flushing}

Analisis reduksi volume sedimen melalui aktivitas flushing, dimaksudkan untuk mengetahui perubahan/ reduksi volume sedimen yang terjadi setelah dilakukan kegiatan flushing. Data yang digunakan adalah data volume flushing sedimen tahun 2008 sampai dengan tahun 2017 yang diperoleh dari PT. Indonesia Power, seperti terdapat pada Tabel 1 dibawah ini.

Tabel 1. Volume dan Reduksi Sedimen Masuk dengan Aktivitas Flushing di Waduk Pangsar Soedirman

\begin{tabular}{rrrrr}
\hline Tahun & $\begin{array}{c}\text { Volume } \\
\text { Sedimen Masuk } \\
\left(\text { juta m }^{\mathbf{3}}\right)\end{array}$ & $\begin{array}{c}\text { Reduksi Volume } \\
\text { Sedimen masuk } \\
\left(\text { juta m }^{\mathbf{3}}\right)\end{array}$ & $\begin{array}{c}\text { Total Volume } \\
\text { Sedimen } \\
\text { Masuk } \\
\left(\mathbf{J u t a ~ m}^{\mathbf{3}}\right)\end{array}$ & $\begin{array}{c}\text { Prosentase Volume } \\
\text { Sedimen Reduksi } \\
(\boldsymbol{\%})\end{array}$ \\
\hline 2008 & 4,241 & 0,058 & 4,299 & 1,349 \\
2009 & 4,634 & 0,129 & 4,763 & 2,708 \\
2010 & 3,518 & 0,536 & 4,054 & 13,222 \\
2011 & 4,599 & 0,719 & 5,318 & 13,520 \\
2012 & 2,706 & 1,435 & 4,141 & 34,653 \\
\hline
\end{tabular}

CIVeng Vol.3, No.1, Januari 2022 : 11 18 


\begin{tabular}{crrrr}
\hline 2013 & 1,290 & 1,190 & 2,480 & 47,984 \\
2014 & 0,056 & 1,651 & 1,707 & 96,719 \\
2015 & 2,934 & 1,421 & 4,355 & 32,629 \\
2016 & 0,597 & 3,041 & 3,638 & 83,590 \\
2017 & 5,059 & 0,510 & 5,569 & 9,158 \\
\hline
\end{tabular}

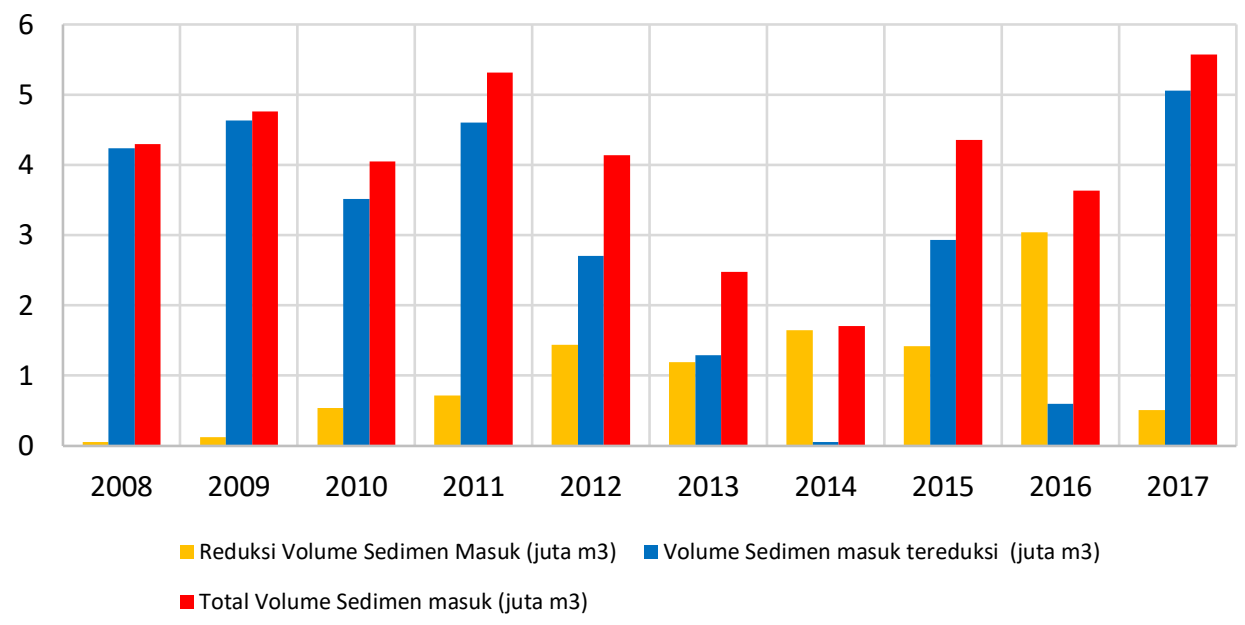

Gambar 5. Volume dan Reduksi Sedimen Masuk dengan Aktivitas Flushing di Waduk Pangsar Soedirman Sumber : Analisis 2019, [3]

\subsection{Analisis Prediksi volume Sedimen 10 tahun Mendatang dengan aktivitas Flushing}

Analisis prediksi volume sedimen melalui aktivitas flushing, dimaksudkan untuk mengetahui prediksi perubahan peningkatan volume sedimen yang terjadi jika dilakukan kegiatan flushing. Analisis dilakukan menggunakan metode statistika. Hasil analisis dapat dilihat pada 2 dan Gambar 6 dibawah ini.

Tabel 2. Prediksi Volume dan Reduksi Sedimen Masuk 2008-2026 Melalui Aktivitas Flushing di Waduk Pangsar Soedirman (juta $\mathrm{m}^{3}$ )

\begin{tabular}{|c|c|c|c|c|}
\hline Tahun & $\begin{array}{c}\text { Prediksi } \\
\text { Volume } \\
\text { Sedimen Masuk } \\
\left(\text { juta } \mathbf{m}^{3}\right)\end{array}$ & $\begin{array}{c}\text { Prediksi Reduksi } \\
\text { Volume Sedimen } \\
\quad \text { (juta m }{ }^{3} \text { ) }\end{array}$ & $\begin{array}{l}\text { Total Volume } \\
\text { Sedimen Masuk } \\
\left(\text { Juta m } \text { m }^{3}\right)\end{array}$ & $\begin{array}{c}\text { Prosentase } \\
\text { Volume } \\
\text { Sedimen } \\
\text { Reduksi (\%) } \\
\end{array}$ \\
\hline 2008 & 4,241 & 0,058 & 4,299 & 1,349 \\
\hline 2009 & 4,634 & 0,129 & 4,763 & 2,708 \\
\hline 2010 & 3,518 & 0,536 & 4,054 & 13,222 \\
\hline 2011 & 4,599 & 0,719 & 5,318 & 13,520 \\
\hline 2012 & 2,706 & 1,435 & 4,141 & 34,653 \\
\hline 2013 & 1,290 & 1,190 & 2,480 & 47,984 \\
\hline 2014 & 0,056 & 1,651 & 1,707 & 96,719 \\
\hline 2015 & 2,934 & 1,421 & 4,355 & 32,629 \\
\hline 2016 & 0,597 & 3,041 & 3,638 & 83,590 \\
\hline 2017 & 5,055 & 0,510 & 5,569 & 9,158 \\
\hline 2018 & 4,057 & 0,453 & 4,510 & 4,510 \\
\hline 2019 & 3,054 & 0,396 & 3,450 & 3,450 \\
\hline 2020 & 3,132 & 0,780 & 3,912 & 3,912 \\
\hline 2021 & 3,211 & 1,163 & 4,374 & 4,374 \\
\hline 2022 & 3,673 & 1,163 & 4,836 & 4,836 \\
\hline 2023 & 4,014 & 1,662 & 5,676 & 5,676 \\
\hline 2024 & 3,771 & 2,161 & 5,932 & 5,932 \\
\hline 2025 & 3,028 & 2,660 & 5,688 & 5,688 \\
\hline 2026 & 2,785 & 3,159 & 5,944 & 5,944 \\
\hline
\end{tabular}

Analisis Operasional Waduk Pangsar Soedirman Untuk Reduksi Peningkatan Sedimen Masuk 


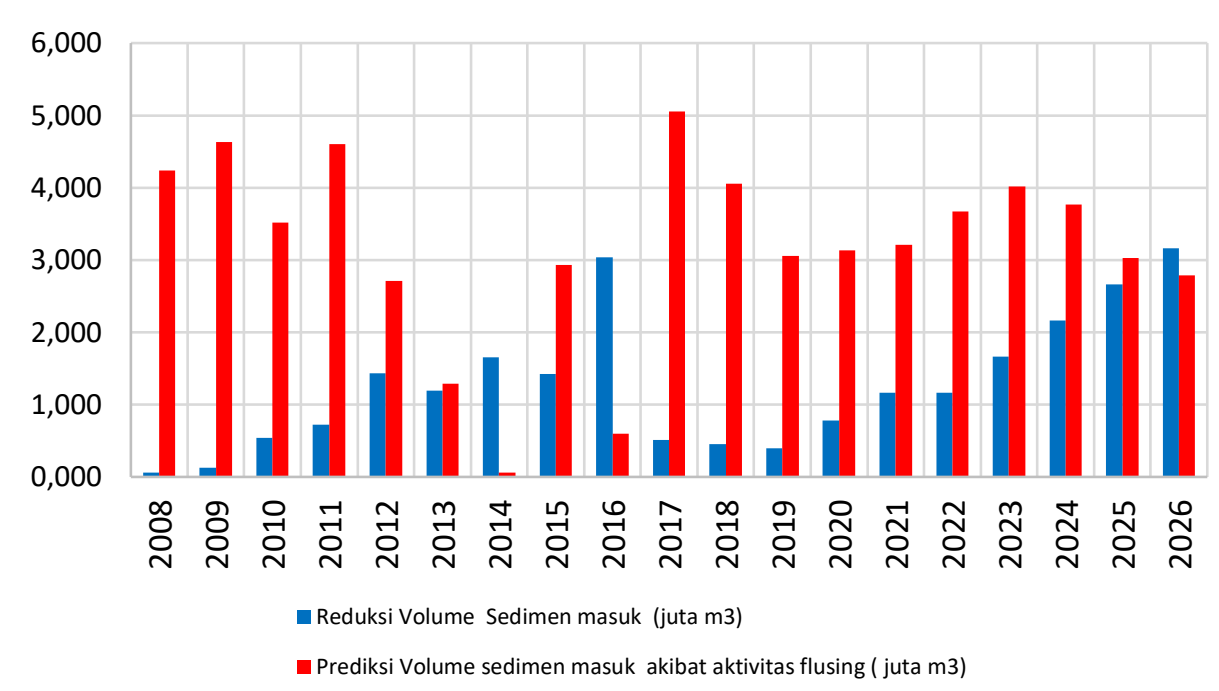

Gambar 6. Prediksi volume dan Reduksi Sedimen Masuk 2008-2026 Melalui Aktivitas Flushing di Waduk Pangsar Soedirman Sumber : Analisis 2019, [3]

\subsection{Analisis Prediksi Volume Sedimen 10 tahun Mendatang tanpa Flushing}

Analisis prediksi volume sedimen tanpa melalui aktivitas flushing, dimaksudkan untuk mengetahui prediksi perubahan peningkatan volume sedimen yang terjadi jika tanpa dilakukan kegiatan flushing. Analisis dilakukan menggunakan metode statistika Log Pearson Tipe III. Hasil analisis dapat dilihat pada Tabel 3 dan Gambar 4 dibawah ini.

Tabel 3. Prediksi Volume Sedimen 2008-2026 tanpa Aktivitas Flushing (juta m³)

\begin{tabular}{cc}
\hline Tahun & $\begin{array}{c}\text { Prediksi Volume Sedimen Masuk tanpa } \\
\text { Aktivitas Flusing } \\
\text { (juta } \mathbf{~ m}^{3} \text { ) }\end{array}$ \\
\hline 2008 & 4,299 \\
2009 & 4,763 \\
2010 & 4,054 \\
2011 & 5,318 \\
2012 & 4,141 \\
2013 & 2,480 \\
2014 & 1,707 \\
2015 & 4,355 \\
2016 & 3,638 \\
2017 & 5,569 \\
2018 & 4,510 \\
2019 & 3,450 \\
2020 & 3,912 \\
2021 & 4,374 \\
2022 & 4,836 \\
2023 & 5,177 \\
2024 & 5,433 \\
2025 & 5,688 \\
2026 & 5,944 \\
\hline Sumber : Analisis, 2019 & \\
& \\
\hline
\end{tabular}

CIVeng Vol.3, No.1, Januari 2022:11 18 


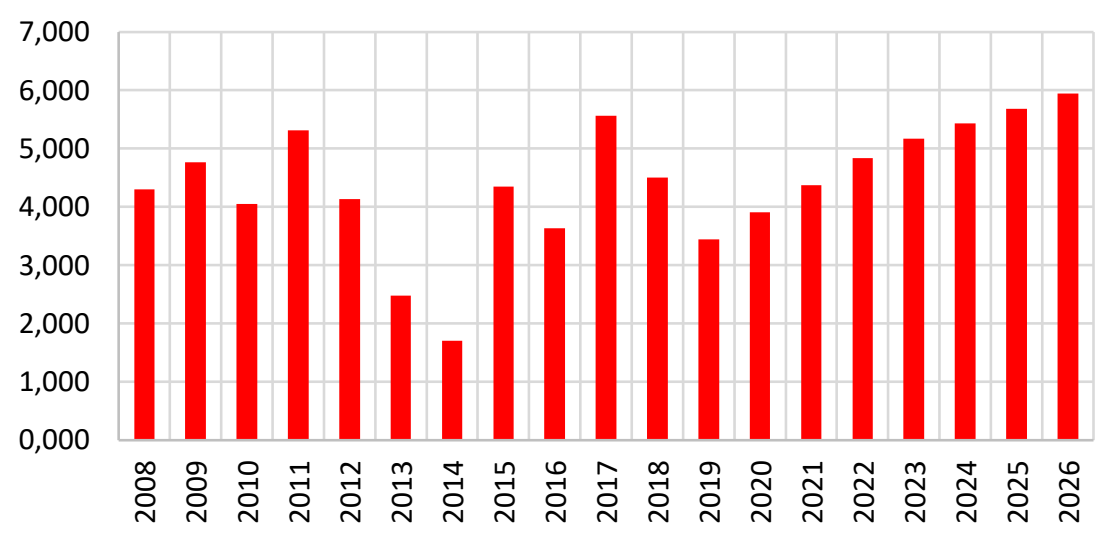

Gambar 7. Prediksi volume Sedimen Masuk 2008-2026 tanpa aktivitas Flushing di Waduk Pangsar Soedirman Sumber : Analisis 2019, [3]

\section{KESIMPULAN}

Berdasarkan hasil analisis dapat disimpulkan sebagai berikut :

1. Prediksi total volume sedimen masuk Waduk Pangsar Soedirman tahun 2018-2026 tanpa aktivitas flushing mencapai 84,464 juta $\mathrm{m}^{3}$.

2. Prediksi total volume sedimen yang tersimpan di Waduk Pangsar Soedirman tahun 2018-2026 dengan aktivitas flushing mencapai 43,321 juta $\mathrm{m}^{3}$.

3. Pengaruh aktivitas flushing selama kurun waktu 2008-2026 mencapai 51,289\%.

\section{DAFTAR PUSTAKA}

[1] Marhendi, Teguh, 2014, "Penentuan Erosi Lahan Menggunakan Formula Usle Dengan Dasar Karakteristik Tanah", Jurnal Techno, vol 15, no. 2, pp 9-14, 2014.

[2] Marhendi, Teguh, 2018, "Prediksi Peningkatan Sedimentasi dengan metode Angkutan Sedimen (Studi Kasus Sedimentasi di Waduk Mrica)”, Jurnal Techno, Vol. 19 No. 2, Oktober 2018, Hal. 87-94, 2018

[3] PT. Indonesia Power Unit Pembangkit Mrica, 2018, Laporan Pelaksanaan Penyelidikan Sedimentasi Waduk PLTA PB. Sudirman", Banjarnegara. 2018

[4] Soewarno, 1992, "Hidrologi Aplikasi Metode Statistik Untuk Analisa Data", Nova, Bandung, 1995.

[5] Ari Wulandari, Dyah, "Penanganan Sedimentasi Waduk Mrica", Jurnal berkala ilmiah teknik keairan vol.13, No.4, 2007

[6] Marhendi, Teguh, 2010, “Analisis Umur Fungsi Waduk Mica”, Jurnal Techno ,vol 10, no. 2, 2010.

[7] Marhendi, Teguh, "Pengaruh Faktor Panjang Kelerengan terhadap Penentuan Awal Erosi Lahan", Jurnal Riset dan Teknologi, LPPM UMP, 2017

[8] Munandar, Aris, dkk, 2014, "Analisis Laju Angkutan Sedimen Bagi Perhitungan Kantong Lumpur pada D.I Perkotaan Kabupaten Batubara”. Teknik Sipil, Universitas Sumatera Utara, Vol 3 No. 4, 2014. 
